\title{
In vitro and in vivo Evaluation of Pharmacological Potential of Lasia spinosa Linn.
}

\author{
Piyali Chowdhury ${ }^{1}$, Mohammed Ibrahim ${ }^{1}$, Sarrin Shahadat ${ }^{1}$, Md. Ruhul Kuddus ${ }^{2}$ \\ and Mohammad A. Rashid ${ }^{2}$
}

\author{
${ }^{1}$ Department of Pharmacy, Southern University Bangladesh, Mehedibag, Chattogram, Bangladesh \\ ${ }^{2}$ Phytochemical Research Laboratory, Department of Pharmaceutical Chemistry, Faculty of Pharmacy, \\ University of Dhaka, Dhaka-1000, Bangladesh
}

(Received: April 05, 2021, 2020; Accepted: June 03, 2021; Published (web): June 20, 2021)

\begin{abstract}
Lasia spinosa Linn. (Family: Araceae) is an important medicinal plant, which is traditionally used for treatment of different human ailments. The present study was undertaken to evaluate the in vitro thrombolytic, antiinflammatory and in vivo analgesic and hypoglycemic potentials of $n$-hexane, chloroform and aqueous soluble fractions of methanol extract of $L$. spinosa whole plant. Additionally, phytochemical screening was carried out by qualitative tests, which confirmed the presence of alkaloids, glycosides, steroids, tannins, saponin in this plant. During in vitro thrombolytic assay, the aqueous fraction at a dose of $500 \mu \mathrm{g} / 100 \mu \mathrm{l}$ showed the maximum $33.15 \%$ lysis of the blood clot, as compared to the standard streptokinase $(80.10 \%)$. The in vitro anti-inflammatory test was performed by inhibition of egg albumin denaturation assay and RBC membrane stabilization method. The chloroform fraction exhibited maximum anti-inflammatory potential by inhibiting $51.53 \%$ denaturation of albumin and by inhibiting 54.8\% hemolysis of RBC membrane against hypotonic solution. Analgesic activity was evaluated by tail immersion method for central mechanism and by formalin-induced lick test for peripheral mechanism in mice. In tail immersion method, all the solvent fractions of $L$. spinosa at a dose of $500 \mathrm{mg} / \mathrm{kg}$ body weight exhibited a significant $(\mathrm{p}<0.05)$ elongation in pain reaction time. In peripheral analgesic activity test, the chloroform fraction at a dose of $500 \mathrm{mg} / \mathrm{kg}$ body weight inhibited a maximum of $35.44 \%$ licking response induced by formalin, as compared to the standard aspirin (53.22\%). In the hypoglycemic activity test, all the fractions showed a moderate effect in reducing the blood glucose level in mice treated with $10 \%$ glucose. In conclusion, the plant $L$. spinosa can be considered as a promising source of bioactive compounds for the development of new phytomedicine.
\end{abstract}

Key words: Lasia spinosa, Thrombolytic, Anti-inflammatory, Analgesic, Hypoglycemic, Phytochemical.

\section{INTRODUCTION}

Medicinal plant is an imperative source of promising lead candidates having therapeutic potential. Plant-derived secondary metabolites can serve as lead compounds and have been extensively studied for the discovery of new pharmaceuticals. Many of the currently used pharmaceuticals are of natural origin. According to World Health Organization (WHO) reports, around $80 \%$ of the world population relies on herbal products. This is because, herbal medicines are cheap and have least side effects, but possess strong pharmacological actions. $^{1-4}$

Correspondence to: Mohammad A. Rashid

E-mail: r.pchem@yahoo.com

Dhaka Univ. J. Pharm. Sci. 20(1): 111-119, 2021 (June)

DOI: https://doi.org/10.3329/dujps.v20i1.54039
Lasia spinosa Linn. is a perennial herb that can grow up to $2 \mathrm{~m}$ in height. The plant is widely distributed in Southeast Asia and habitually, it grows in lowland areas, rivers banks, ditches, moist place near water bodies. In Bangladesh, the plant is familiar as 'Kantakachu' or 'Kaful'. The plant has enormous traditional applications in the treatment of rheumatism and intestinal disorders. The plant shoots are edible. ${ }^{5}$ In Bangladesh, the tribal people in Khagrachari use its rhizomes as a remedy for throat infections, whereas leaves and rhizomes together are used for the management of piles. ${ }^{6}$ Also, people in Rajshahi and Natore of the country use tubers for treatment of rheumatoid arthritis and constipation. ${ }^{7}$ The plant rhizome also possess antioxidant ${ }^{8}$, antimicrobial and cytotoxic ${ }^{9}$ activities. In Srilanka 
and Malaysia, the rhizome is frequently used as a remedy for hemorrhoids. Preliminary phytochemical screening confirmed the presence of bioactive phytochemicals such as flavonoids, alkaloids, saponins, carbohydrates and phenolic compounds in the different extracts of this plant species. ${ }^{10,11}$

There are several reports on multifarious biological actions of $L$. spinosa, but to the best of our knowledge, we herein, report the blood clot lysis ability and RBC membrane stabilizing potential of this plant for the first time. Additionally, analgesic and hypoglycemic properties of $L$. spinosa were also evaluated using animal model.

\section{MATERIALS AND METHODS}

Plant collection and identification. $L$. spinosa was collected from the wetland of Chandanaish, Chattogram in December, 2018. The botanical samples were authenticated by a taxonomist Mr. Md. Syedul Alam at Bangladesh Forest Research Institute (BFRI), Chattogram, Bangladesh, where a voucher sample (Accession no: BFRIH-471/SA) was deposited for future reference.

Extraction and partitioning of the plant extract. After collection, the plants were cleaned, sun-dried for several days and then ground to a coarse powder using a grinder and then stored in an airtight container at room temperature until their further uses.

Approximately $245 \mathrm{~g}$ of powdered sample of $L$. spinosa was soaked in $1.0 \mathrm{~L}$ methanol in an amber bottle for 10 days. The whole mixture was then filtered by cotton plug followed by Whatman No. 1 filter paper. The filtrate was evaporated to dryness using a rotary evaporator (Heidolph, Germany) at $40^{\circ} \mathrm{C}$ under reduced pressure $(\sim 2.10 \mathrm{psi})$. The concentrated gummy mass, also designated as a methanol extract of $L$. spinosa whole plant was transferred to a clean beaker. Later, modified Kupchan method ${ }^{12}$ was followed to obtain the $n$ hexane (HFLS), chloroform (CFLS) and aqueous (AFLS) soluble fraction of $L$. spinosa with the weight of $1.8 \mathrm{~g}, 3.5 \mathrm{~g}$ and $4.2 \mathrm{~g}$, respectively. All these plant samples, designated as HFLS, CFLS, and AFLS were subjected for the evaluation of pharmacological potential of L. spinosa.

Chemicals and reagents. Streptokinase, aspirin, glibenclamide were collected as gift samples from Square Pharmaceuticals Ltd, Bangladesh. Morphine (Morphine G) was collected from Gonoshasthaya Pharmaceuticals Ltd, Bangladesh. All the chemicals and reagents employed in this experiment were of analytical grade.

Animals. Swiss albino mice (20-25 g) of either sex were obtained from Bangladesh Council of Scientific and Industrial Research (BCSIR), Chattogram, Bangladesh. The animals were housed at room temperature $\left(26 \pm 2^{\circ} \mathrm{C}\right)$ with $12 \mathrm{~h} \mathrm{light/ \text {dark }}$ cycle for 1 week to adjust the standard laboratory conditions. All experiments were carried out according to the standard guidelines.

Preliminary phytochemical screening. Qualitative tests $^{13}$ were performed to confirm the phytochemical nature of different solvent fractions of L. spinosa.

In vitro thrombolytic activity. The different solvent fractions of methanol extract of L. spinosa whole plant were evaluated for the thrombolytic activity using streptokinase (SK) as the standard. ${ }^{14}$ In brief, $5 \mathrm{ml}$ venous blood was collected from healthy volunteers and distributed in sterile alpine tubes $(0.5$ $\mathrm{ml} /$ tube). The tubes were incubated at $37^{\circ} \mathrm{C}$ for 45 min. After clot formation, the serum was completely removed without disturbing the clot and each tube having blood clot was again weighed to determine the clot weight. To each alpine tube containing preweighed clot, $100 \mu \mathrm{l}$ of solutions of different solvent fractions $(500 \mu \mathrm{g} / 100 \mu \mathrm{l})$ were added separately. Next, $100 \mu \mathrm{l}$ of streptokinase (as the positive control), $100 \mu \mathrm{l}$ of distilled water (negative control), $n$-hexane, chloroform and aqueous solution were separately added to the tubes. All the tubes were then incubated at $37^{\circ} \mathrm{C}$ for $90 \mathrm{~min}$ for clot lysis. After incubation, the released fluid was removed and the tubes were again weighed to observe the difference in weight after clot disruption. The following formula was used to determine the extent of clot lysis. 


$$
\% \text { Clot lysis }=\frac{\text { Weight of released clot }}{\text { Weight of blood clot }} \times 100
$$

\section{In vitro anti-inflammatory activity}

Inhibition of albumin denaturation. To determine the anti-inflammatory effect of $L$. spinosa, albumin denaturation inhibition assay was performed according to the method described by Ibrahim et al. ${ }^{15}$ Briefly, three sterile tubes were labelled as positive, negative and test group, that received $2.0 \mathrm{ml}$ of aspirin $(0.1 \mathrm{mg})$, Tween-80 and plant sample (500 $\mu \mathrm{g} / \mathrm{ml}$ ), respectively. Then, $0.2 \mathrm{ml}$ of $5 \%$ egg albumin solution and $2.8 \mathrm{ml}$ phosphate buffer $(\mathrm{pH} 6.4 \pm 0.2)$ were added to all test tubes. The reaction mixtures were incubated at $37^{\circ} \mathrm{C}$ for $15 \mathrm{~min}$ and then heated at $70^{\circ} \mathrm{C}$ for $5 \mathrm{~min}$. After filtering the reaction mixture, the absorbance of the filtrate was measured spectrophotometrically at $660 \mathrm{~nm}$ (Shimadzu-1800). The percent inhibition of protein denaturation was calculated by using the following formula ${ }^{16}$ :

$\%$ inhibition of protein denaturation $=\frac{A_{\text {control }}-A_{\text {test }}}{A_{\text {control }}} \times 100 \%$

Here, $A=$ Absorbance for respective group.

Erythrocyte membrane stabilization. Membrane stabilization method ${ }^{17}$ is usually employed to evaluate in vitro anti-inflammatory activity of plant extract or chemical substance. In our investigation, three sterile tubes were labeled as positive, negative and test group, accordingly. Then, $1 \mathrm{ml}$ of phosphate buffer $(\mathrm{pH} 7.4 \pm 0.2), 2 \mathrm{ml}$ of hyposaline and $0.5 \mathrm{ml}$ of human erythrocyte suspension were added to all these tubes. Later on, 1 $\mathrm{ml}$ of aspirin $(0.1 \mathrm{mg})$ and $1 \mathrm{ml}$ of distilled water were taken in the standard and control tubes, respectively, while $1.0 \mathrm{ml}$ of plant samples (500 $\mu \mathrm{g} / \mathrm{ml}$ ) was mixed to the test group as marked. All the reaction mixtures were incubated at $37^{\circ} \mathrm{C}$ in a BOD (Biological oxygen Demand) incubator for $30 \mathrm{~min}$ and then centrifuged at $3000 \mathrm{rpm}$ for $10 \mathrm{~min}$. After cooling and filtering, the absorbance of the supernatants was measured at $560 \mathrm{~nm}$. The in vitro anti-inflammatory potential of $L$. spinosa via its membrane stabilization activity was determined by measuring the $\%$ inhibition of hypotonic solutioninduced hemolysis as follows.
$\%$ inhibition of hemolysis $=\frac{A_{\text {control }}-A_{\text {test }}}{A_{\text {control }}} \times 100 \%$

Here, $A=$ Absorbance for respective group.

\section{Analgesic activity}

Central analgesic activity. Tail immersion test ${ }^{18}$ was employed to determine the central analgesic activity of $L$. spinosa in mice. In this assay, the animals were divided into negative control, positive control or standard and test groups containing three mice in each. Prior to any treatment, each mouse was weighed properly and the doses of test samples and control materials were adjusted accordingly. Test groups received the test samples (HFLS, CFLS, AFLS at $500 \mathrm{mg} / \mathrm{kg}$ body weight) orally, while the positive and negative control group received standard drug morphine (2 $\mathrm{mg} / \mathrm{kg}$ body weight, subcutaneously) and saline, respectively. After the treatment of each group, at zero-hour, $1-2 \mathrm{~cm}$ of the tail of mice was immersed in a beaker of warm water maintained at $55^{\circ} \mathrm{C}$. The pain reaction time is the time required by the mice to deflect their tails. Following the oral administration of plant sample/drugs, pain reaction time was measured at $0,30,60$ and $90 \mathrm{~min}$ and the results were compared with the control group.

Peripheral analgesic activity. The peripheral analgesic activity of $L$. spinosa in mice was determined by formalin-induced lick test. ${ }^{19}$ In this assay, the animals were divided into negative control, positive control or standard and test groups as mentioned in the above section. At zero-hour, test samples (HFLS, CFLS, AFLS at $500 \mathrm{mg} / \mathrm{kg}$ body weight), control and standard aspirin $(50 \mathrm{mg} / \mathrm{kg}$ ) were administered orally. After $30 \mathrm{~min}$, formalin (1\%) was administered subcutaneously to each of the animals. Licking and biting responses were measured during the first $5 \mathrm{~min}$ after formalin injection. The percent inhibition of formalin-induced licking response was then calculated by the following equation:

$\%$ inhibition of licking $=\frac{\mathrm{N}_{\text {control }}-\mathrm{N}_{\text {test }}}{\mathrm{N}_{\text {control }}} \times 100 \%$

Where, $\mathrm{N}=$ Mean number of licking and biting responses for each group. 
Hypoglycemic activity. Hypoglycemic activity was evaluated by oral glucose tolerance test (OGTT) ${ }^{20}$ In this assay, the experimental animals were also divided into negative control, standard and test groups containing three mice in each group. At zero-hour, test samples (HFLS, CFLS, AFLS at 500 $\mathrm{mg} / \mathrm{kg}$ body weight), control and standard glibenclamide $(10 \mathrm{mg} / \mathrm{kg}$ body weight $)$ were administered orally. After 60 min of administration of the plant sample, mouse of all groups was orally treated with $10 \%$ glucose solution $(2 \mathrm{mg} / \mathrm{kg}$ body weight). Blood glucose level was measured at 30, 60 and $120 \mathrm{~min}$ of glucose loading by a glucometer.

Statistical analysis. Experimental data were presented as mean \pm SEM. Data were analysed by Student's $t$-test using GraphPad Software, USA. The result was considered significant, when $\mathrm{p}<0.05$.

\section{RESULTS AND DISCUSSION}

Beside the phytochemical analysis, the $n$-hexane, chloroform and aqueous soluble fractions of methanol extract of $L$. spinosa whole plant were subjected for the evaluation of in vitro thrombolytic, anti-inflammatory as well as in vivo analgesic and hypoglycemic potential. And the results were summarized in Table 1 and Figure 1-5.

The therapeutic properties of medicinal plants arise from its phytochemicals such as alkaloids, flavonoids, tannins and glycosides. The phytochemical screening of different solvent fractions of $L$. spinosa revealed the presence of various phytochemicals such as alkaloids, glycosides, steroids, tannins, saponin reducing sugars and gums (Table 1). The result of this preliminary screening is in agreement with previous studies ${ }^{10,11}$, where various extracts of both rhizome and root of $L$. spinosa contains a lot of secondary metabolites as mentioned in Table 1.

In Bangladesh, the traditional medicinal practitioners, also familiar as Kabiraj use a variety of medicinal plants for treatment of cardiovascular diseases. Thrombolytic agents of plant source are usually low-priced, affordable and less toxic and this the reason of their uses by the local traditional medicine prescribers. ${ }^{21,22}$ Therefore, $L$. spinosa was screened for thrombolytic activity using human RBC and the results were presented in Figure 1. The aqueous (AFLS) and chloroform (CFLS) soluble fractions of methanol extract of $L$. spinosa at the dose of $500 \mu \mathrm{g} / 100 \mu \mathrm{l}$ showed significant thrombolytic activity by clot lysis of $33.15 \%$ and $32.29 \%$, respectively, as compared to the standard streptokinase (80\%). Distilled water (served as the negative control) exhibited a negligible percentages of clot lysis (4.17\%). Phytoconstituents such as tannins, alkaloids and saponins demonstrated a significant clot lysis activity through the breakdown of fibrinogen and fibrin in a clot. ${ }^{23}$ The results of our initial phytochemical analysis revealed that different solvent fractions of $L$. spinosa whole plant extracts possess tannin, alkaloid and saponin which could be associated with their clot lysis ability observed in the study.

Table 1. Phytochemical screening of $\boldsymbol{n}$-hexane, chloroform and aqueous fractions of methanol extract of $L$. spinosa whole plant.

\begin{tabular}{lccc}
\hline Phytochemical & \multicolumn{3}{c}{ Plant sample } \\
\cline { 2 - 4 } & $\begin{array}{c}n \text {-Hexane } \\
\text { fraction }\end{array}$ & $\begin{array}{c}\text { Chloroform } \\
\text { fraction }\end{array}$ & $\begin{array}{c}\text { Aqueous } \\
\text { fraction }\end{array}$ \\
\hline Alkaloids & - & - & + \\
Glycosides & + & + & - \\
Steroids & + & - & - \\
Tannins & + & + & + \\
Flavonoids & - & - & - \\
Saponins & - & - & + \\
Reducing & - & + & + \\
sugars & - & - & + \\
Gums & - & + & + \\
Amides & & & + \\
\hline
\end{tabular}

'+' = present, '-'= absent

The management of inflammation with NSAIDs, a most commonly used type of anti-inflammatory drug, has serious health complications such as gastric irritation, gastric ulcers. In contrast, plant-based medicine is relatively safe, cheap and popular in common people. Medicinal plants serve as one of the most prominent sources of bioactive lead with significant anti-inflammatory activities. ${ }^{24}$ Therefore, in this study $L$. spinosa was subjected for the 
assessment of in vitro anti-inflammatory potential by inhibition of egg albumin denaturation assay method.

Denaturation of albumin is related with the pathogenesis of inflammatory diseases. ${ }^{25,26}$ By inhibition of albumin denaturation, inflammatory activity can be inhibited. Therefore, any compound that can inhibit the protein denaturation, would be considered as a promising candidate for antiinflammatory drug development.

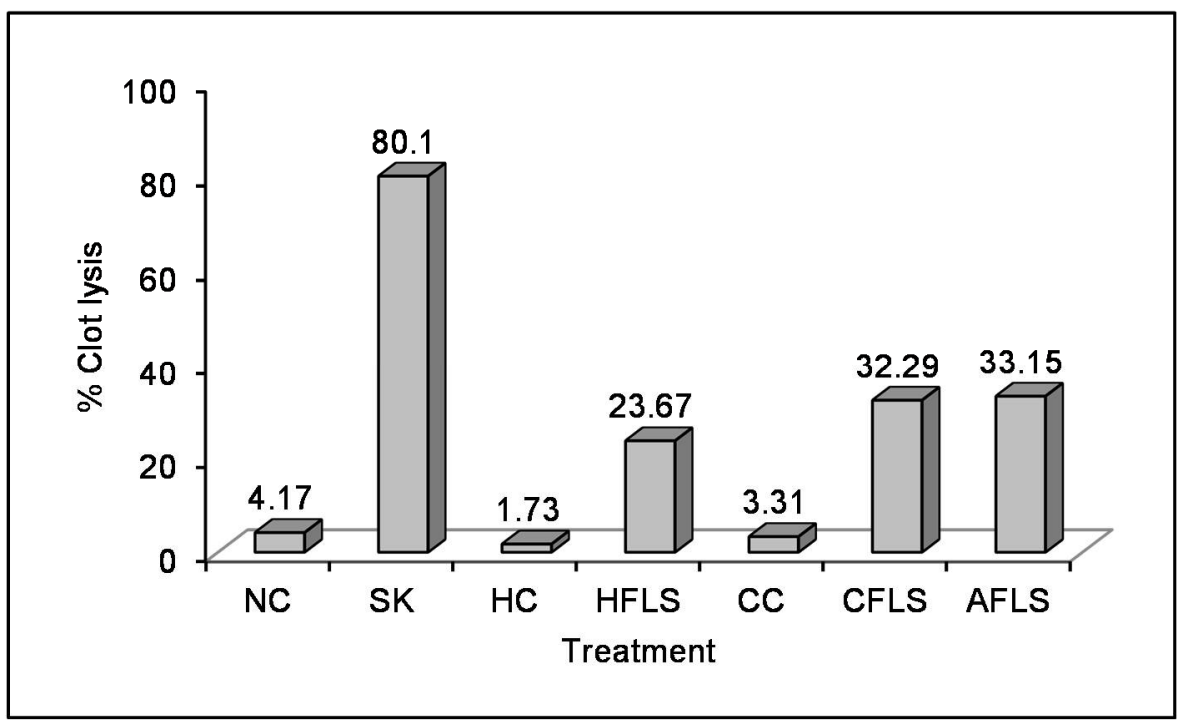

Figure 1. Thrombolytic activity of $n$-hexane, chloroform and aqueous soluble fractions of methanol extract of $L$. spinosa. Here, NC $=$ Negative control, $\mathrm{HC}=\mathrm{n}$-hexane control; $\mathrm{CC}=$ chloroform control.
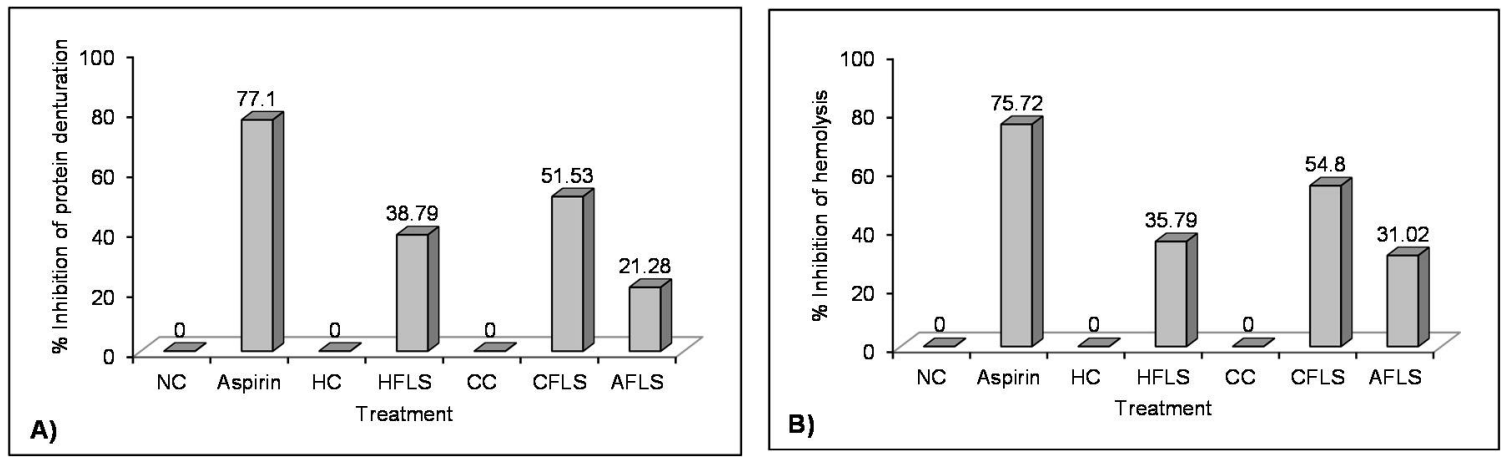

Figure 2. Anti-inflammatory activity of $n$-hexane, chloroform and aqueous soluble fractions of methanol extract of $L$. spinosa by inhibition of albumin denaturation (A) and by erythrocyte membrane stabilization method (B).

In the present study, the ability of all the solvent fractions of methanol extract of $L$. spinosa to inhibit albumin denaturation was found to be statistically significant $(\mathrm{p}<0.05)$. The chloroform fraction at the dose of $500 \mu \mathrm{g} / \mathrm{ml}$ showed the highest inhibition capacity with $51.53 \%$, followed by $n$-hexane $(38.79 \%)$ and aqueous fraction $(21.28 \%)$, while the standard aspirin exhibited $77.10 \%$ inhibition of albumin denaturation (Figure 2A).
Anti-inflammatory activity of $L$. spinosa was further confirmed by employing the membrane stabilization method $^{27}$ using human erythrocyte. Human erythrocyte membranes are similar to the liposomal membrane, so the prevention of hypotonic solution-induced lysis of erythrocyte membrane has been used as a measure for estimating the antiinflammatory property of plant extract. ${ }^{27}$ Similar to albumin assay, the various solvent fractions of $L$. 
spinosa also showed a significant $(\mathrm{p}<0.05)$ inhibition of the erythrocyte membrane hemolysis. As shown in Figure 2B, the chloroform fraction showed a maximum inhibition of hemolysis induced by hypotonic solution with 54.8\%. However, in both assay methods, none of the control group (NCnegative control; HC- $n$-hexane control; CCchloroform control) had any inhibitory effect, suggesting that only the plant constituents in the test samples produced anti-inflammatory effect. The results were compared with the standard aspirin, which showed $75.72 \%$ inhibition of hypotonic solution- induced hemolysis (Figure 2B). All the solvent fractions exhibited membrane stabilization by inhibiting hypotonic solution-induced lyses of the erythrocyte membrane, and its stabilization implies that the plant, $L$. spinosa may stabilize lysosomal membranes. Stabilization of liposomal membrane is important in inhibiting the inflammatory response at the site of injury. Previous studies explained the antiinflammatory properties of roots and leaves extract of L. spinosa in experimental animal. ${ }^{5,28}$ The methanol extract of $L$. spinosa leaves at a dose of $400 \mathrm{mg} / \mathrm{kg}$ body weight reduced the carrageenan-induced edema by $76.53 \%$ after $4^{\text {th }} \mathrm{h}$ injection of carrageenan in mice. ${ }^{5}$ Similarly, the hydroalcoholic extract of root of L. spinosa at doses of $250-$ and $500 \mathrm{mg} / \mathrm{kg}$ body weight produced a dose-dependent and significant anti-inflammatory activity that was carried out by both the xylene-induced ear edema model and carrageenan-induced paw edema model mice. ${ }^{28}$ Our present investigation is a study of whole plant for the claimed biological effect of the same plant. Comparable to the previous studies, the current study showed that the different solvent fractions of $L$. spinosa whole plant possess promising antiinflammatory potential via the mechanism of albumin denaturation inhibition and RBC membrane stabilization method.

Central analgesic activity was evaluated by tail immersion method which is based on observation that morphine-like drugs can prolong the reaction time of tail withdrawal reflex in mice. A constant heat stress is applied to mouse tail, which acts as a pain stimulus. When the stimulus exceeds the threshold, mouse show a quick withdrawal of its tail. Time taken by the mouse to withdraw the tail is termed as tail immersion time. ${ }^{29}$ Centrally acting analgesics elongate this responding time. In our study, the control group showed faster tail flicks at different time intervals of the experiment (Figure 3). All the fractions of $L$. spinosa induced a significant $(\mathrm{p}<0.05)$ increased in pain reaction time, that is comparable to standard drug morphine. Here, we can see that the chloroform fraction at a dose of $500 \mathrm{mg} / \mathrm{kg}$ body weight demonstrated a significant increase in pain reaction time after $90 \mathrm{~min}$ of administration in mice.

Along with tail immersion method, analgesic activity was also evaluated by formalin test for peripheral mechanism. ${ }^{19}$ Administration of formalin into the right hind paw of the experimental animals causes and induces inflammation through production of prostaglandin in biological system. Any agent that reduces the number of licking responses will reveal analgesia in animal by inhibition of prostaglandin synthesis, a peripheral mechanism of pain inhibition. ${ }^{29}$ During formalin test, the chloroform fractions at $500 \mathrm{mg} / \mathrm{kg}$ body weight showed maximum analgesic activity with $35.44 \%$ inhibition of licking responses induced by formalin, whereas aspirin at a dose of $10 \mathrm{mg} / \mathrm{kg}$ body weight exhibited $53.22 \%$ inhibition. Our observed result showed that the analgesic effect of $L$. spinosa is too peripherally mediated. Similarly, Deb et $a ._{.}{ }^{28}$ reported that root extract of $L$. spinosa significantly reduced the level of analgesia in experimental animal by acetic acidinduced writhing test and hot plate method, which is a resemblance to the observation of Goshwami et al. ${ }^{5}$ The results (Figure 4) from the formalin test showed that the solvent fractions from whole plant extract of L. spinosa also exhibited peripherally acting analgesic property. Thus, it could be concluded that the plant species $L$. spinosa exhibited analgesic activity by central as well as peripheral mechanism. The observed analgesic and anti-inflammatory activities may be due to the presence of phytoconstituents like alkaloids, glycoside, steroids and saponins. 


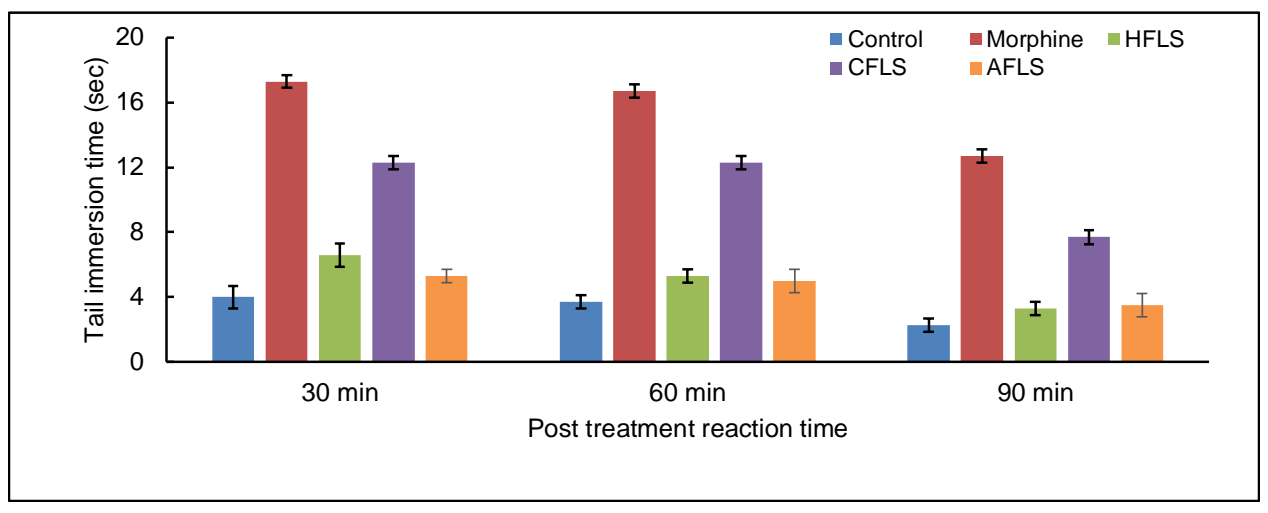

Figure 3. Central analgesic activity of $n$-hexane, chloroform and aqueous soluble fractions of methanol extract of $L$. spinosa in tail immersion test.

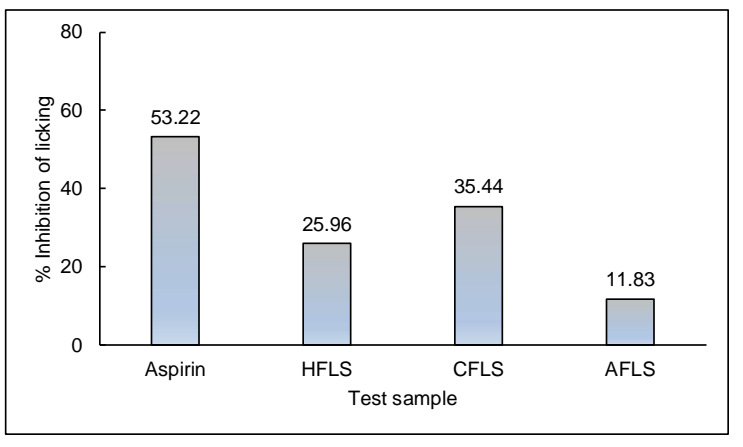

Figure 4. Peripheral analgesic activity of $n$-hexane, chloroform and aqueous soluble fractions of methanol extract of $L$. spinosa in formalin-induced lick test.

Due to the drawbacks of synthetic medicines, plant-based compounds with antidiabetic potential can be used as an alternative approach in the treatment of diabetes. Globally, more than 1200 species of medicinal plants are used in folkloric medicine for their antidiabetic activity. ${ }^{30}$ Therefore, the researchers have been searching the plant sources to find out the bioactive molecule with glucose lowering potential. In the oral glucose tolerance test, the glucose loaded diabetic mice were treated with different solvent fractions of $L$. spinosa. As shown in Figure 5, all the plant extracts $(500 \mathrm{mg} / \mathrm{kg})$ reduced blood glucose level at $0,30,60,120 \mathrm{~min}$ of experiment, compared to the control group. This effect was persistent for up to 120 min after the oral administration of glucose. Hasan et al. ${ }^{31}$ also reported the anti-hyperglycemic effects of methanolic and ethanolic extracts of leaf of $L$. spinosa plant, where the methanolic extract showed better activity

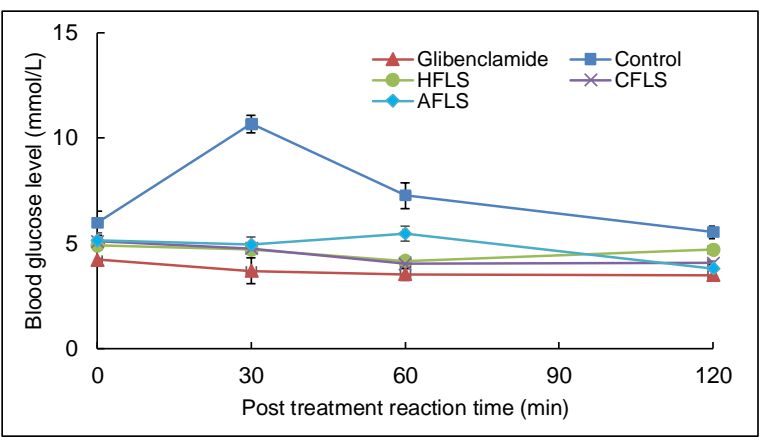

Figure 5. Hypoglycemic activity of $n$-hexane, chloroform and aqueous soluble fractions of methanol extract of L. spinosa in mice.

compared to the ethanolic extract. The plant extracts can reduce the plasma glucose level probably by stimulation of insulin secretion by $\beta$-cells or inhibition of pancreatic $\alpha$-amylase, or by accelerating the uptake of glucose by peripheral tissues. ${ }^{32}$ Further biological investigations are needed to confirm the mechanism of these pharmacological actions.

\section{CONCLUSION}

In conclusion, the present study demonstrated that the $n$-hexane, chloroform and aqueous soluble fractions of methanol extract of whole plant of $L$. spinosa possess significant thrombolytic, antiinflammatory and analgesic effects in mice model. Such activities may be linked with the presence of bioactive compounds like alkaloids, glycoside, steroids and saponins in the plant sample. Nonetheless, further research is indispensable to 
identify the bioactive compounds present in this plant.

\section{REFERENCES}

1. Newman, D.J. and Cragg, G.M. 2016. Natural products as sources of new drugs from 1981 to 2014. J. Nat. Prod. 79, 629-661.

2. Cragg, G.M. and Newman, D.J. 2013. Natural products: a continuing source of novel drug leads. Biochim. Biophys. Acta. 1830, 3670-3695.

3. Sen, T. and Samanta, S.K. 2015. Medicinal plants, human health and biodiversity: a broad review. Adv. Biochem. Eng. Biotechnol. 147, 59-110.

4. Huang, F., Li, Y., Leung, E.L., Liu, X., Liu, K., Wang, Q., Lan, Y., Li, X., Haibing, Y., Liao, C., Luo, H. and Luo, L. 2020. A review of therapeutic agents and Chinese herbal medicines against SARS-COV-2 (COVID-19). Pharmacol. Res. 158, 104929.

5. Goshwami, D., Rahman, M.M., Muhit, M.A. and Islam, M.S. 2013. Antinociceptive, anti-inflammatory and antipyretic activities of methanolic extract of Lasia spinosa Leaves. Int. J. Pharm. Chem. Sci. 2, 118-122.

6. Yusuf, M., Chowdhury, J.U., Wahab, M.A. and Begum, J. 1994. Medicinal Plants of Bangladesh. Bangladesh Council of Scientific and Industrial Research. Dhaka, Bangladesh, pp. $1-340$.

7. Rahmatullah, M., Jahan, R., Azad, A.K. et al. Miajee, Z.U.M.E. 2010. Medicinal plants used by folk medicinal practitioners in three villages of Natore and Rajshahi districts, Bangladesh. Am. Eurasian J. Sustain Agric. 4, 211218.

8. Shefana, A.G. and Ekanayake, S. 2009. Some nutritional aspects of Lasia spinosa (kohila). Vidyodaya J. Sci. 14, 5964.

9. Hasan, C.M., Alam, F., Haque, M., Sohrab, M.H., Monsur, M.A. and Ahmed, N. 2011. Antimicrobial and cytotoxic activity from Lasia spinosa and isolated Lignan. Lat. Am. J. Pharm. 30, 550-553.

10. Lakshmi, M.A., Priya, G.V. and Rao, B.G. 2020. Morphoanatomical feature and phytochemical assessments of Lasia spinosa (L) Thwaites. Indian J. Pharm. Sci. 82, 891-901.

11. Kumar, M., Mondal, P., Borah, S. and Mahato, K. 2013. Physico-chemical evaluation, preliminary phytochemical investigation, fluorescence and TLC analysis of leaves of the plant Lasia spinosa (Lour) Thwaites. Int. J. Pharm. Sci. 5, 306-310.

12. VanWagenen, B.C., Larsen, R., Cardellina, J.H., Randazzo, D., Lidert, Z.C. and Swithenbank, C. 1993. Ulosantion, a potent insecticide from the sponge Ulosa ruetzleri. J. Organomet. Chem. 58, 335-337.
13. Mahmood, N., Nazir, R., Khan, M., Iqbal, R., Adnan, M., Ullah, M. and Yang, H. 2019. Phytochemical screening, antibacterial activity and heavy metal analysis of ethnomedicinal recipes and their sources used against infectious diseases. Plants, 8, 454.

14. Mahfuz, A., Salam, F.B.A., Deepa, K.N. and Hasan, A.H.M.N. 2019. Characterization of in-vitro antioxidant, cytotoxic, thrombolytic and membrane stabilizing potential of different extracts of Cheilanthes tenuifolia and stigmasterol isolation from $n$-hexane extract. Clin. Phytosci. $\mathbf{5}, 39$.

15. Ibrahim, M., Hossain, A., Shajib, S. and Rashid, M.A. 2018. Preliminary phytochemical and pharmacological screenings of Plumbago indica L . and Alpinia conchigera Griff . Dhaka Univ. J. Pharm. Sci. 17, 73-79.

16. Banerjee, S., Chanda, A., Adhikari, A., Das, A. and Biswas, S. 2014. Evaluation of phytochemical screening and antiinflammatory activity of leaves and stem of Mikania scandens (L.) Wild. Ann. Med. Health Sci. Res. 4, 532-536.

17. Uddin, J., Julie, A., Ali, M. H., Islam, M. N., Khan, S. and Labu, Z. 2016. Antimicrobial, thrombolytic, membrane stabilizing activities and total flavonoid content of various partitionates of aerial parts of Eclipta alba (L.) Hassk. Dhaka Univ. J. Pharm. Sci. 14, 207-213.

18. Aziz, M.A., Mehedi, M., Akter, M.I., Sajon, S.R., Mazumder, K. and Rana, M.S. 2019. In vivo and in silico evaluation of analgesic activity of Lippia alba. Clin. Phytosci. 5, 38

19. Demsie, D.G., Yimer, E.M., Berhe, A.H., Altaye, B.M. and Berhe, D.F. 2019. Anti-nociceptive and anti-inflammatory activities of crude root extract and solvent fractions of Cucumis ficifolius in mice model. J. Pain Res. 12, 13991409.

20. Mansur, M.A., Siddiqi, M.M. and Saha, K. 2018 Thrombolytic, membrane stabilizing and hypoglycemic activities of Anethum sowa Linn. Dhaka Univ. J. Pharm. Sci. 17, 237-241.

21. Sharmin, S., Kabir, M.T., Islam, M.N., Jamiruddin, M.R., Rahman, I., Rahman, A. and Hossain, M. 2018. Evaluation of antioxidant, thrombolytic and cytotoxic potentials of methanolic extract of Aporosa wallichii Hook.f. leaves: an unexplored phytomedicine. J. Appl. Pharm. Sci. 8, 51-56.

22. Hussain, F., Islam, A., Bulbul, L., Moghal, M.R. and Hossain, M.S. 2014. In vitro thrombolytic potential of root extracts of four medicinal plants available in Bangladesh. Anc. Sci. Life 33, 162-164.

23. Das, A. and Dewan, S.M. 2013. Investigation of in vitro thrombolytic potential and phytochemical nature of Crinum latifolium L. leaves growing in coastal region of Bangladesh. Int. J. BioPharma. Res. 4, 1-7. 
24. Nunes, C.D.R., Barreto Arantes, M., Menezes de Faria Pereira, S., Leandro da Cruz, L., de Souza Passos, M., Pereira de Moraes, L., Vieira, I.J.C. and Barros de Oliveira, D. 2020. Plants as sources of anti-inflammatory agents. Molecules, 2020, 25.

25. Dharmadeva, S., Galgamuwa, L.S., Prasadinie, C. and Kumarasinghe, N. 2018. In vitro anti-inflammatory activity of Ficus racemosa L. bark using albumin denaturation method. Ayu, 39, 239-242.

26. Osman, N.I., Sidik, N.J., Awal, A., Adam, N.A. and Rezali, N.I. 2016. In vitro xanthine oxidase and albumin denaturation inhibition assay of Barringtonia racemosa $\mathrm{L}$. and total phenolic content analysis for potential anti-inflammatory use in gouty arthritis. J. Intercult. Ethnopharmacol. 5, 343-349.

27. Parameswari, P., Devika, R. and Vijayaraghavan, P. 2019. In vitro anti-inflammatory and antimicrobial potential of leaf extract from Artemisia nilagirica (Clarke) Pamp. Saudi J. Biol. Sci. 26, 460-463.

28. Deb, D., Dev, S., Das, A.K., Khanam, D., Banu, H., Masum, S., Ayesha, A., Choudhuri, M.S.K. and Basher, S.A.M.K. 2010. Antinociceptive, anti-inflammatory and anti-diarrheal activities of the hydroalcoholic extract of Lasia spinosa Linn. (Araceae) Root. Lat. Am. J. Pharm. 29, 1269-1276.
29. Bhuiyan, M.M.R., Bhuiya, N.M.M.A., Hasan, M.N. and Nahar, U.J. 2020. In vivo and in silico evaluation of antinociceptive activities of seed extract from the Holarrhena antidysenterica plant. Heliyon 6, e03962.

30. Alema, N.M., Periasamy, G., Sibhat, G.G., Tekulu, G.H. and Hiben, M.G. 2020. Antidiabetic activity of extracts of Terminalia brownii Fresen. stem bark in mice. J. Exp. Pharmacol. 12, 61-71.

31. Hasan, M.N., Munshi, M., Rahman, M.H., Alam, N. and Hirashima, A. 2014. Evaluation of antihyperglycemic activity of Lasia spinosa leaf extracts in swiss albino mice. World $J$. Pharm. Sci. 3, 118-124.

32. Njogu, S.M., Arika, W.M., Nyamai, D.W., Ngugi, M.P., Machocho, A.K., Ngeranwa, J.J.N. and Njagi, E.N.M. 2016. Hypoglycemic effect of aqueous and ethyl acetate leaf extract of Maytenus putterkloides in alloxan-induced diabetic mice. J. Diabetes Metab. 7, 685, Article ID:1000685. 